\title{
The Impact of Sexual Harassment Policy in the Dutch Police Force
}

\author{
Stans de Haas • Greetje Timmerman • Mechtild Höing • \\ Miriam Zaagsma $\cdot$ Ine Vanwesenbeeck
}

Published online: 12 November 2009

(C) The Author(s) 2009. This article is published with open access at Springerlink.com

\begin{abstract}
The aim of the present study was to evaluate the outcome of sexual harassment policy in the Dutch Police Force. Using a survey, sexual harassment was measured in 2000 and again in 2006 and we tested whether sexual harassment is associated with the comprehensiveness of policies. To be able to identify divisions with comprehensive policies, we interviewed 29 key persons in semi-structured interviews. It appeared that between 2000 and 2006 sexual harassment did not decrease: neither for women nor for men. Furthermore, the risk of sexual harassment was not lower in divisions that implemented comprehensive policies than in divisions with less comprehensive policies. The results suggest that sexual harassment is a workplace hazard that is very difficult to prevent in male dominated workplaces and implementing a comprehensive policy is not sufficient to prevent this workplace hazard.
\end{abstract}

Key words sexual harassment $\cdot$ male dominance $\cdot$ prevention $\cdot$ evaluation

Sexual harassment occurs frequently in many organizations (Fitzgerald et al. 1997a). Metaanalytic data from the United States show that one out of every four women has experienced sexual harassment at work (Ilies et al. 2003). Victims often have low job satisfaction, low affective commitment, mental and physical health problems and higher intentions to leave the organization (Willness et al. 2007). A frequently used psychological definition of sexual harassment was formulated by Fitzgerald et al. (1997b) as "unwanted sex-related behavior at work that is appraised by the recipient as offensive, exceeding her resources or threatening well-being" (p. 15). Sexual harassment is continuously present

S. de Haas $(\bowtie) \cdot$ M. Höing $\cdot$ M. Zaagsma $\cdot$ I. Vanwesenbeeck

Rutgers Nisso Group, Utrecht, The Netherlands

e-mail: s.dehaas@rng.nl

G. Timmerman

Behavioral and Social Sciences, Gender studies, University of Groningen, Groningen, The Netherlands e-mail: m.c.timmerman@rug.nl 
since women entered the (male dominated) workplace (Bonate and Jessell 1996), and it is unlikely that it will decrease without intervention. The aim of this study is to evaluate the outcome of the measures against sexual harassment that have been taken by the Dutch police force.

Organizations in most Western countries are obliged by law to prevent sexual harassment in the workplace and to protect employees from the negative effects, such as the loss of their job or acts of retaliation. In the Netherlands, organizations are obliged to set up a grievance procedure; to conduct a risk analysis to identify what the problem is, its extent and its nature; and to appoint confidential advisors (Kolner et al. 2006). Confidential advisors have four main tasks. Firstly, they should prevent sexual harassment, for example by promoting a safe climate at work. Secondly, they should give advice to policymakers and thirdly, anonymously register complaints. Fourthly, they should support victims of sexual harassment, act to stop harassment, either through informal or through formal channals and protect victims of the possible negative consequences of filing a complaint (Transact and Rutgers Nisso Groep 2007).

Because anti sexual harassment programs and policies are obligatory and because a growing number of organizations acknowledge the detrimental effects of sexual harassment, most organizations have developed an anti sexual harassment program. Studies evaluating the impact of anti sexual harassment practices are scarce (Bingham and Scherer 2001; Gallivan Nelson et al. 2007), though some researchers have identified working components of anti sexual harassment policy.

\section{Sexual Harassment Policy in Organizations}

Gruber (1998) evaluated the effect of organizational policy by comparing the incidence of sexual harassment in three groups of women: female employees who indicate that their organization has no policy, procedures or training against sexual harassment; women who report that their organization employs informative methods (pamphlets and posters); and those who judge the organizational policy as proactive or change-oriented (e.g. explicit grievance procedures and training programs). It appeared that sexual harassment was reported more often by women who state that the organization practices informational methods than women who perceive their organization as proactive. This could imply that proactive methods are more effective compared to informative methods.

Furthermore, sexual harassment is more likely to occur in organizations where anti sexual harassment training is not provided and which are perceived to spend minimal effort to enforce policies and procedures related to sexual harassment and to provide few services to the victims of sexual harassment (Harned et al. 2002). In addition, sexual harassment is less prevalent in organizations that employ confidential advisors and have set up a grievance procedure specifically designed to tackle sexual harassment than in organizations that either did not appoint confidential advisors or do not have a specific grievance procedure (Amstel and Volkers 1993). Hulin et al. (1996) identified organizational tolerance of sexual harassment as a critical predictor. They found that the incidence of sexual harassment increases when victims perceive that complaining may have negative effects, expect that their complaints will not be taken seriously and consider meaningful sanctions unlikely.

Policies not directly aimed at sexual harassment seem to be effective too. Research in a telecommunication company in the Netherlands revealed that rates of reported sexual harassment are lower in workplaces that are perceived as employee-oriented rather than job- 
oriented. In employee-oriented workplaces there is not only a concern to get the job done, but concern for people is important too. Furthermore, male and female employees who perceive their organization as sensitive to the difficulties of balancing professional life with family and personal life experience less sexual harassment than women and men who are working in companies that prioritize on corporate rather than personal or family role demands. Finally, employees who judge the attitude of their department as positive toward the equal treatment of men and women at work less frequently report having experienced sexual harassment (Timmerman and Bajema 2000).

\section{Sexual Harassment Policy in the Police Force}

Sexual harassment policies are especially important in male dominated organizations, because women who work in predominately male workplaces experience more instances of sexual harassment than women in more gender-balanced workplaces (Gutek et al. 1990; Gruber and Morgan 2005) and as the ratio of male co-workers increases women are more likely to have experienced sexual harassment (Jackson and Newman 2004). Therefore women employed in male dominated organizations are more at risk of sexual harassment than other working women (Kauppinen-Toropainen 1991). This is especially true for police women who are, as a minority group, highly visible members in the male dominated organization of law enforcement (Kauppinen and Patoluoto 2005). A survey study among serving policewomen from 35 countries revealed that $77 \%$ experienced sexual harassment from colleagues (Brown and Heidensohn 2000).

The risk of an unbalanced male to female ratio suggests that employing women may be an effective preventive strategy. On the other hand, as the minority grows, the majority will lose its dominant position. As a result the majority may preserve its power by harassing female co-workers (Ott 1989). This hypothesis was supported by a study of Brown and Heidensohn (2000). In their sample of police women they found a U-shaped relation between sexual harassment and gender ratio. Sexual harassment occurred the least in gender- balanced workplaces, but increased when police women were either in the minority or in the majority. It seems that when men are in the minority they use sexual harassment as a way to restore their sense of control and to preserve their access to organizational benefits, whereas when men are in the majority they sexually harass women to reinforce the token status of women.

Male dominated organizations are not only characterized by skewed sex-ratios. According to Gruber and Morgan (2005) male dominance is a multi-faceted concept, consisting of at least two dimensions: numerical and normative male dominance. Organizations that are numerically dominated by men have many more male than female employees. In normatively male dominated organizations traditional masculine values are usually rewarded. The devaluation of women, sexual bravado, aggression, emotional selfregulation, risk taking and technological competence are typical features of these organizations (Timmerman 2005). Both numerical and normative male dominance are related to sexual harassment (Gruber and Morgan 2005).

Besides efforts aiming at reducing numerical male dominance, organizations may also aim to reduce normative male dominance. For example, to improve the position of female police officers, in late 1980s and early 1990s the police service in Great Britain introduced equal opportunities policies by distributing a full statement of this policy and an abbreviated form of the grievance procedure on an explanatory leaflet (Martin 1996). After this introduction Martin conducted a study in a sample of officers in one division of 
the Sussex police. It appeared that seven of the nine interviewed female police constables experienced physical sexual harassment. Although all women were aware of various grievance procedures, only one woman made a complaint about the behavior of her colleagues. Most of the women felt able to deal with harassment personally. Because sexual harassment took place behind close doors or was not reported, not all supervisors knew of these incidents and all male staff thought that sexual harassment was not widespread. The results of Martin's study suggest that the distribution of the explanatory leaflet did raise awareness of the grievance procedure, but did not prevent sexual harassment.

\section{Sexual Harassment Policy in the Dutch Police Force}

Since the early 1990s sexual harassment policies have been implemented in the Dutch police force. The Dutch police force is organized in one national and 25 regional divisions, which operate independently and make their own policies. In addition, all divisions have representatives in different national committees and boards, for example the National Expertise Centre Diversity (LECD) that provides advice for regional policy. Across divisions, $33 \%$ of the police officers are female. Between the divisions there is little variability in this percentage $(S D=3.4)$, with the exception of one division where $23 \%$ of the officers are female. In 2000 most divisions had formally written guidelines regarding sexual harassment. Furthermore, confidential advisors were appointed and committees for complaints were established. In most divisions preventive measures were restricted to the recruitment of women, in order to limit the skewed male to female ratio. Changing the organizational culture and creating commitment among management and staff has received limited attention until 2000 (Sandfort and Vanwesenbeeck 2000).

During the following years, and especially from 2004/2005 onwards, sexual harassment policy became more comprehensive. First, the grievance procedure has changed. Initially, only sexual harassment could be reported. In 2006 also complaints about other forms of harassment could be submitted.

Secondly, confidential advisors were trained to fulfill their two main tasks. They should both support victims of sexual harassment as well as proactively prevent sexual harassment by informing personnel about anti sexual harassment policies and stimulating managers to prevent sexual harassment in their teams. In general, the first task was fulfilled by all confidential advisors. The quality, frequency and intensity of the execution of the second task depended on the personal commitment of the confidential advisor. In addition, in most divisions managing confidential advisors were appointed to coordinate the work of the confidential advisors and to improve sexual harassment policies.

Thirdly, the police force has invested in the improvement of the position of female police officers with several measures. Divisions selectively recruited women to reduce the skewed male-female ratio. Further, women were supported and stimulated to promote to higher ranks, for example by offering assessments to detect leadership talent and by creating opportunities to practice leadership skills. In addition, women were stimulated to organize networks of female police officers. Also, reasons for turnover of women were investigated with exit-interviews. Finally, possibilities to work part time were improved.

Fourthly, managers and employees were informed about anti sexual harassment policies and procedures. In some divisions only new trainees were informed, whereas other divisions informed their employees repeatedly. Furthermore, managers were also trained to stop sexual harassment. For example, managers were trained to recognize sexual harassment in an early stage, so that they could prevent it to escalate. Education was also 
aimed at changing the organizational culture. In some divisions managers were judged on their social and preventive skills in selection procedures or in performance or employee appraisal (De Haas et al. 2007).

\section{The Present Study}

The aim of the present study is twofold. First we aim to evaluate the outcome of the measures that have been taken between 2000 and 2006 in the Dutch police force. If these measures have been successful, sexual harassment may be less prevalent. We, therefore, compared the occurrence of sexual harassment in 2000 with 2006 and investigated whether there were differences between 2000 and 2006. As we wanted to allow for both positive and negative effects, no expectations about the direction of the effect were formulated.

The second aim of this study is to investigate whether the occurrence of sexual harassment is associated with the comprehensiveness of the policies. Previous research shows that written policy statements and providing information about sexual harassment are the first steps towards preventing sexual harassment. Also training seems to have an effect. Efforts to change the organizational culture (e.g. by employing more women to reach gender balance or by improving opportunities for women) may also be effective. Furthermore, confidential advisors and grievance procedures also seem to be effective means to prevent sexual harassment. This suggests that a comprehensive anti sexual harassment policy should include written policy statements, preventive efforts aiming to change the organizational culture, a grievance procedure, information and training, and confidential advisors. In contrast, a less comprehensive policy does not include all these aspects. To test whether the occurrence of sexual harassment is positively associated with the comprehensiveness of the policies we compared divisions with comprehensive and less comprehensive policies. This could provide policy makers with information about necessary elements of anti sexual harassment policy.

\section{Method}

Procedure

In 2000 and again in 2006 a police labor union commissioned a study of sexual harassment, bullying and diversity in the Dutch Police Force. The 2006 study was a replication of the 2000 study. Both studies were executed by the Rutgers Nisso Groep, the Dutch Expert Center on Sexuality, and the same questionnaire was used in both studies. For the present study we used the sexual harassment data.

In 2000 and again in 2006 participants were invited in a letter that was sent to their home addresses to fill out a questionnaire. There were some differences between the 2000 and the 2006 study. In 2000, addresses of the participants were obtained through the administration of Police Health Service (DGVP), which was the health care insurance company of all police officers. On behalf of the DGVP a paper and pencil questionnaire was sent out among equally sized representative groups of police women and men. There was no incentive and no reminder to fill out the questionnaire. In 2006 an introduction letter was sent out among a representative group of police officers. As a result of a reorganization of the Dutch health care insurance system, in 2006 the Police Health Service did not exist anymore. Therefore, the second survey was sent out on behalf of the police labor union that commissioned the study. Respondents were invited to anonymously fill out an internet questionnaire either at home or at work. The 
questionnaire was placed on the internet by the Dutch police academy. As an incentive, one out of every hundred respondents received a book token of $€ 25$. After 4 weeks all respondents received a written reminder to fill out the questionnaire.

To be able to identify divisions with comprehensive policies we interviewed key persons in 16 divisions in semi-structured interviews. The interviews were conducted between March 2006 and June 2006 and ranged in length from $1 \mathrm{~h}$ to $2 \mathrm{~h}$. All interviews were tape recorded and transcribed. To increase efficiency irrelevant utterances were omitted. In addition, the key persons were asked to provide the researchers with all written policy statements and documentation about implemented practices that were produced between 2000 and 2006. Subsequently, it was assessed whether the divisions had written policy statements, preventive efforts aiming to change the organizational climate, a grievance procedure, information and training, and confidential advisors.

\section{Participants}

In 2000 , a response rate of $39 \%$ to the survey resulted in a sample of 6,387 police officers, of which $53 \%$ were men and $47 \%$ were women. The average age was 43 years for police men $(s d=8.25)$ and 35 years for police women $(s d=7.90)$. Three percent of both the police men and women were from ethnic minority groups, such as Surinamese, Turkish or Moroccan. Of the men $85 \%$ worked as executives (graduated from the police academy and qualified for the core business of police work and law enforcement) and $23 \%$ were part of the managerial staff (in charge of a team of police officers). Among women these percentages were $51 \%$ and $7 \%$ respectively.

In 2006, 3,001 police men and 1,295 police women filled out the questionnaire. The average age was 45 years for police men $(s d=9.72)$ and 39 years for police women $(s d=9.40)$. Because the average age in 2000 was lower than the average age in 2006, and because age is related to sexual harassment (Sbraga and O'Donohue 2000), we controlled for age when sum scores are compared. As the police force recruited more among ethnic minorities in the past few years, in the 2006 sample the percentage of ethnic minority representatives doubled to $6 \%$. With regard to job status the percentages in the 2006 sample are comparable to the 2000 sample: $83 \%$ of the men in the 2006 sample worked as executives and $22 \%$ were part of the managerial staff. Among women these percentages were 51\% and $8 \%$ respectively. In 2006, the response rate was $15 \%$. Despite the low response rate the sample was representative for gender, age and job status. Low response rate was possibly partly due to questionnaire overload and technical problems with getting the internet questionnaire started.

For the interviews, we selected 29 employees from 16 divisions of the Dutch police force. The selected employees played a central role in the development and implementation of anti sexual harassment practices. Most key persons were managing confidential advisors. Three selected key persons did not cooperate. One of them refused because sexual harassment had already been studied in the police force. The other said that his or her position was at stake and he or she did not want to jeopardize that further. The third was absent due to illness. The latter two were replaced by colleagues, who were also wellinformed about the division's policy.

\section{Measurements}

We used both questionnaires and interviews. In 2000 and in 2006 the questionnaires included questions relating to demographic aspects and sexual harassment. The 2006 survey was specifically designed to replicate the 2000 questionnaire. The Dutch adaptation 
of the Sexual Experience Questionnaire (SEQ; Fitzgerald et al. 1988; Fitzgerald et al. 1995) was used to measure sexual harassment. Three items measuring gender harassment were deleted, because gender harassment may not be suitable to measure sexual harassment of men (Magley et al. 1999). These items were replaced by others that were found to be applicable to the police context in a preliminary investigation among 20 police officers. The translation from English into Dutch made some minor changes in formulation necessary. The Dutch version presents 18 sexually harassing behaviors and asks respondents to indicate frequency of having experienced these personally from superiors or co-workers during the previous 24 months. Scores are on a five-point scale ranging from ' $1=$ never', via ' $2=$ once or twice', ' $3=$ sometimes' and ' $4=$ regularly' to ' $5=$ often'.

Factor analyses on our data revealed two factors. The first, Unwanted Sexual Attention and Advances, consists of 12 items referring to forms of verbal and behavioral harassment (Cronbach's alpha $=.83$ ). The second, Sexual Coercion, consists of six items referring to behaviors where resistance, promises or retaliation are at stake (Cronbach's alpha=.69). The two factor structure was inconsistent with the three factor structure that was found with the revision of the SEQ of 1995 (Fitzgerald et al. 1995). Replacing the three gender harassment items by three other items measuring unwanted sexual attention and advances may explain this inconsistency. Because everybody who experienced sexual coercion also experienced unwanted sexual attention and advances, sum scores of the total scale were used in the analyses. Cronbach's alpha for the total scale is .87 .

The SEQ was originally designed to measure sexual harassment of women. Differential test function for men and women was investigated for the Department of Defense version of the SEQ (SEQ-DoD), which is almost similar to the original version of the SEQ. It appeared that the SEQ-DoD functioned equivalently across men and women when four items were removed (Donovan and Drasgow 1999). We had already removed three of these four items, as we omitted three items measuring gender harassment. One item of the four items was retained ('Stared, leered, or ogled you in a way that made you feel uncomfortable'). In our sample $48 \%$ of the men who were confronted with this type of sexual harassment were bothered by it, making it a relevant item. Therefore, we retained it.

During the interviews the key persons were asked whether the policy of their division included preventive measures (changing the organizational climate by recruiting women or by creating equal opportunities for men and women), grievance procedures, publicity of information and training. We also asked whether their division employed confidential advisors. Divisions with a written policy statement, preventive efforts aiming to change the organizational climate, a grievance procedure, information and training, and confidential advisors were labeled as having a comprehensive policy. Divisions who did not have all these aspects were labeled as less comprehensive.

\section{Results}

\section{Descriptive Statistics}

In $200069 \%$ of the police women reported experience of at least one type of sexual harassment at least a few times. In 2006 this percentage was 64\%. Controlled for age, the decrease was not significant $(b=-.05, p=.54$, odds ratio=.96). For men, there was a significant increase of $44 \%$ to $48 \%(b=.11, p=.03$, odds ratio=1.12). It appeared that eight divisions had comprehensive policies, whereas the policies in another eight divisions were less comprehensive. One of the latter had no written policy statement, in three divisions 
training was not provided and in four divisions no preventive efforts were implemented. One of the divisions that did not take preventive measures, neither had a complaint procedure. In the divisions with comprehensive policies $67 \%$ of the women and $49 \%$ of the men were sexually harassed at least a few times. In the divisions with less comprehensive policies these percentages were somewhat lower: $62 \%$ for women and $48 \%$ for men. Neither for women $(b=.16, p=.31$, odds ratio $=1.17)$ nor for men $(b=.02, p=.84$, odds ratio $=1.02)$ were there significant differences between the divisions.

\section{Comparison Between 2000 and 2006}

As an indication for the impact of the efforts of the Dutch police to tackle sexual harassment, we tested whether sexual harassment decreased using analyses of variance for men and women separately, while controlling for age. We present results separately for men and women because the impact of sexual harassment programs may differ between men and women (Bingham and Scherer 2001). For women sexual harassment scores slightly decreased (Table 1), but the difference was not significant $(F(1 ; 4003)=.16, p=.69)$. For men sum scores significantly increased $(F(1 ; 5784)=6.77, p=.01)$ (Table 1$)$.

\section{Sexual Harassment and the Comprehensiveness of the Policies}

We tested whether sexual harassment is more prevalent in divisions with less comprehensive policies than in divisions with comprehensive policies. We used analyses of variance and controlled for age, because the mean age varied across the divisions and sexual harassment is related to age (Sbraga and O'Donohue 2000). For both women and men sexual harassment scores were somewhat lower in divisions with less comprehensive policies (Table 2). The difference was not significant either for women $(F(1 ; 673)=.54$, $p=.46)$ or for men $(F(1 ; 1690)=.34, p=.56)$.

The divisions with less comprehensive policies can be divided into three categories: divisions without written policy statements; without training; and without preventive efforts. These categories were compared with each other and with the comprehensive divisions, using analyses of variance. Again, controlled for age, there were no differences between these divisions for women $(F(1 ; 671)=.38, p=.77)$ or for men $(F(1 ; 1688)=.42, p=.74)$.

\section{Discussion}

The first aim of the present study was to evaluate the outcome of sexual harassment policy in the Dutch police force. It appeared that in 2006 the percentage of women who

Table 1 Mean sum scores, standard deviations (SD) and effect sizes (d) for women and men in 2000 and 2006.

\begin{tabular}{|c|c|c|c|c|c|c|}
\hline & \multicolumn{3}{|c|}{ Women } & \multicolumn{3}{|l|}{ Men } \\
\hline & Mean & SD & $\mathrm{d}$ & Mean & $\mathrm{SD}$ & $\mathrm{d}$ \\
\hline 2000 & 21.35 & 4.46 & 0.06 & 19.32 & 2.23 & -0.05 \\
\hline 2006 & 21.13 & 4.74 & & $19.46^{\wedge}$ & 2.35 & \\
\hline
\end{tabular}

\ Significantly higher than in 2000

$\mathrm{d}=\left(\mathrm{M}_{1}-\mathrm{M}_{2}\right) / \sqrt{ } \mathrm{MS}_{\text {error }}$ 
Table 2 Mean sum scores, standard deviations (SD) and effect sizes (d) for women and men in divisions with comprehensive and less comprehensive policies.

\begin{tabular}{|c|c|c|c|c|c|c|}
\hline & \multicolumn{3}{|c|}{ Women } & \multicolumn{3}{|l|}{ Men } \\
\hline & Mean & $\mathrm{SD}$ & $\mathrm{d}$ & Mean & SD & $\mathrm{d}$ \\
\hline Divisions with comprehensive policies & 21.61 & 5.16 & 0.11 & 19.50 & 2.43 & 0.05 \\
\hline Divisions with less comprehensive policies & 21.07 & 4.77 & & 19.39 & 2.23 & \\
\hline
\end{tabular}

$\mathrm{d}=\left(\mathrm{M}_{1}-\mathrm{M}_{2}\right) / \sqrt{ } \mathrm{MS}_{\text {error }}$

experienced sexual harassment was not significantly lower than in 2000. Moreover, men reported sexual harassment more frequently. Despite the efforts of the Dutch police force sexual harassment is still present in this organization and in the last 6 years the percentage of men and women who experienced this form of workplace harassment did not decrease.

Our results suggest that sexual harassment is very difficult to prevent in a male dominated organization like the police force. Similar results were found in the U.S. military. In 1988 a survey study revealed that sexual harassment was widespread in the military: $73 \%$ of the U.S military women had experienced sexual harassment. Subsequently, the public became aware of various incidents. In response, a zero tolerance program was created and enforced. The program included education and complaint procedures and focused on investigation and adjudication. In 1995 the sexual harassment survey was readministrated and it appeared that the prevalence of sexual harassment was decreased to $59 \%$, which suggests that the program had some impact, but as a preventive tool it was not fully effective (Firestone and Harris 2003). In addition, the results from the U.S. military show that changes are usually not realized overnight: After 7 years of zero tolerance policy still $59 \%$ of female military personnel was sexually harassed. Likewise, in the Dutch police force most preventive measures were realized in recent years and possibly it is too early to see the impact of these measures.

The increased report of sexual harassment among men could be the result of increased awareness. It is also possible that men may try to lose their status as perpetrators by reporting they are victimized. The fact that men were more often harassed in 2006 than in 2000 could also be an indication of adverse effects of the anti sexual harassment program. Because the effect size was small, we believe this would be premature to conclude. However, sexual harassment of men should be closely monitored and measures should be taken if this negative trend would continue.

The second aim of the present study was to investigate whether sexual harassment is less prevalent in divisions with comprehensive policies. No differences were found according to the attributed comprehensiveness of the policy, which suggest that implementing a comprehensive anti sexual harassment policy alone may not be sufficient to prevent sexual harassment. The dynamics at work seem to be more complex. For example, in the City of Los Angeles, female City workers, including female police officers, knew through training that the City government did not approve or condone sexual harassment or gender discrimination. However, fear of having to work in an unfriendly workplace and other acts of retaliations or feelings that it would not make a difference kept many of the female workers from filing formal complaints (Commission on the Status of Women 2005). In addition, federal employees who recently have been harassed, generally perceived their agency's sexual harassment training as ineffective to reduce or prevent sexual harassment (Newman et al. 2003). 
The quality of sexual harassment policy seems to be very important. For example, it has been suggested that organizations should vigorously demonstrate a climate intolerant of sexual harassment. All complaints should be taken seriously, complainants should be offered protection against retaliation and perpetrators should be hold responsible for their actions (Bergman et al. 2002). Furthermore, in order for changes to become widespread and acceptable to the existing male-dominated culture, commitment is needed from within the structure of the police organization. In order to be effective, equal opportunities policies cannot be statements of intent communicated from the top ranks in an organization, rather they need to be incorporated into the ethos of all work units and valued and supported by the all employees in all ranks (Martin 1996).

Our study is not without limitations. Possible shifts in appraisal by those experiencing sexual harassment may blur the interpretation of changes in reported experience of sexual harassment. As the police force spent great efforts to stop sexual harassment, the awareness of harassment could have been increased, which in turn may have had an effect on the report of it. Furthermore, the outcome of the measures that have been taken may not be reflected in the prevalence of sexual harassment. Possibly, police men and women may be better able to cope with sexual harassment because the police organization provides more resources to deal with sexual harassment. Also, it could be possible that more perpetrators meet consequences of their behavior and victims may be more satisfied with interventions. Although, coping or dealing with harassment are important outcomes, they were beyond the scope of the present study. How victims cope or deal with sexual harassment is highly dependent on the context and the specific situation and qualitative interviews could provide insight in coping strategies and the way victims deal with their experiences.

Secondly, the sample could be biased due to the low response rate. Because no systematic non response data are available, reasons for the low response rate are unknown. Low response rate in 2006 was possibly due to questionnaire overload. Respondents also experienced technical problems with getting the internet questionnaire started. Although the response rate was low, the sample was representative for age, gender and job status. Low response rates could bias prevalence rates of sexual harassment: In studies with low response rates reported prevalence of sexual harassment is usually higher than in studies with higher response rates (Gruber 1990). As such the low response rate in 2006 compared to 2000 could have biased the results. If the response rate would have been equal in both studies, there might have been a decrease in sexual harassment. On the other hand, the prevalence rate in our studies was comparable to other similar studies in which sexual harassment was measured with the same instrument. For example, in the British army, the prevalence was $68 \%$ (Rutherford et al. 2006).

Thirdly, the use of retrospective self-report measures may result in bias due to memory problems, because respondents have to think back over quite a lengthy period of time. The alternative for retrospective self-report measures would be observational methods. However, it is clear that such methods are not suitable for workplace harassment research. Therefore, self-report instruments are the most likely measures of choice in studying sexual harassment (Arvey and Cavanaugh 1995). Another limitation regarding the measurement of sexual harassment is the validity of the questionnaire for men. Although we removed items measuring gender harassment, because they may not be suitable to measure sexual harassment of men, possibly the questionnaire could be made more sensitive to potential harassing behavior for men. Qualitative research revealed that allegations of rape or poor sexual performance are potential harassing behaviors for men (Lee 2000). In future research such male-specific items should be included in the questionnaire. 
Fourthly, we were not able to compare restrictive with comprehensive policies. In the Dutch police force all divisions developed some measures against sexual harassment. It could be possible that differences were found when organizations without or with very limited measures were compared with organizations with fully comprehensive policies. In other words: It could be that our measure of comprehensiveness was not sensitive enough to reveal any differences.

Fifthly, we evaluated whether the quantity of sexual harassment policy had an impact on the occurrence of sexual harassment. In future studies researchers should go to the next level and evaluate the quality of sexual harassment programs, to shed some light on the conditions and mechanisms that determine or obstruct the success of organizational practices against sexual harassment. In future research qualitative techniques should be used to distinguish between different policies.

Notwithstanding these limitations, our study contributes to the sexual harassment literature because we evaluated the outcome of measures against sexual harassment in a real life organization. Moreover, we studied reported behavioral outcomes rather than proximal outcomes such as knowledge and attitudes. In previous research often student samples were used and proximal outcomes variables are common in most of the evaluative studies in the field. However, with proximal outcomes, impact can only be shown to a limited extent. Using a representative sample of actual employees is necessary to obtain external validity (Bingham and Scherer 2001). Thus, our study is relatively unique because we link policy to the occurrence of sexual harassment measured on two points in time in an actual organization.

To conclude, in the past 6 years the Dutch police force spent great efforts to tackle sexual harassment. And whereas most organizations do not evaluate their anti sexual harassment programs, the Dutch police force acknowledged the need for evaluation and cooperated with this study. It appeared that in 2006 police officers did not report significantly less experiences with sexual harassment than in 2000. Implementing a comprehensive anti sexual harassment policy did not seem to be sufficient to prevent sexual harassment. Possibly, the quality of the policy is more important. In future research, qualitative techniques should be used to provide more insight in the complex mechanisms that define what works and what does not to stop sexual harassment in male dominated organizations.

Acknowledgements The data reported were gathered by the Rutgers Nisso Groep, the Dutch Expert Centre on Sexuality, as part of a larger study, which was commissioned by the Dutch Police Union (NPB) and financed by the Grant Committee Labour Market and Educations Police (SAOP). During the research process the researchers (Mrs De Haas, MSc, Mrs Zaagsma, MSc, Mrs. Höing MSc, Mrs Van Berlo, MSc, and Mrs. Vanwesenbeeck, PhD) were advised by a committee with representatives of the NPB (Mr Van Duijn and Mrs Van de Putte) and the SAOP (Mrs Hooijenga), as well as the Police Labor Union ACP (Mr Van de Kamp and Mr. Van der Pal), the Ministry of the Interior and Kingdom Relations (Mrs Broek, Mrs Hovius and Mr. Marsman) and the Dutch Police Institute (Mr. Diepenbach). Data were gathered with support of the chiefs of the 26 Dutch police corpses.

Open Access This article is distributed under the terms of the Creative Commons Attribution Noncommercial License which permits any noncommercial use, distribution, and reproduction in any medium, provided the original author(s) and source are credited.

\section{References}

Amstel, R., \& Volkers, H. J. (1993). Seksuele intimidatie: voorkomen en beleid voeren. Ervaringen bij 50 arbeidsorganisaties. [Sexual harassment: prevalence and policy. Experiences at 50 organizations]. Den Haag: Sdu Uitgeverij Plantijnstraat. 
Arvey, R. D., \& Cavanaugh, M. A. (1995). Using surveys to assess the prevalence of sexual harassment: Some methodological problems. Journal of Social Issues, 51, 39-52.

Bergman, M. E., Day Langhout, R., Palmieri, P. A., Cortina, L. M., \& Fitzgerald, L. F. (2002). The (un) reasonableness of reporting: antecedents and consequences of reporting sexual harassment. Journal of Applied Psychology, 87, 230-242.

Bingham, S. G., \& Scherer, L. L. (2001). The unexpected effects of a sexual harassment educational program. Journal of Applied Behavioral Science, 37, 125-153.

Bonate, D. L., \& Jessell, J. C. (1996). The effect of educational intervention on perceptions of sexual harassment. Sex Roles, 35, 751-763.

Brown, J. M., \& Heidensohn, F. (2000). Gender and policing: Comparative perspectives. New York: St. Martin's Press, LLC.

Commission on the Status of Women. (2005). Report on the city of Los Angeles 2005 sexual harassment and gender discrimination survey. Los Angeles: Commission on the Status of Women.

Donovan, M. A., \& Drasgow, F. (1999). Do men's and women's experience of sexual harassment differ? An examination of the differential test functioning of the Sexual Experience Questionnaire. Military Psychology, 11, 265-282.

Fitzgerald, L. F., Shullman, S. L., Bailey, N., Richards, M., Swecker, J., Gold, Y., et al. (1988). The incidence and dimensions of sexual harassment in academia and the workplace. Journal of Vocational Behavior, 32, 152-175.

Fitzgerald, L. F., Gelfand, M. J., \& Drasgow, F. (1995). Measuring sexual harassment: theoretical and psychometric advances. Basic and Applied Psychology, 17, 425-445.

Fitzgerald, L. F., Drasgow, F., Hulin, Ch L, Gelfand, M. J., \& Magley, V. J. (1997a). Antecedents and consequences of sexual harassment in organizations: a test of an integrated model. Journal of Applied Psychology, 82(4), 578-589.

Fitzgerald, L. F., Swan, S., \& Magley, V. J. (1997b). But was it really sexual harassment? Legal, behavioral, and psychological definitions of workplace victimization of women. In W. O'Donohue (Ed.), Sexual harassment: Theory, research, and treatment (pp. 5-28). Boston: Allyn and Bacon.

Firestone, J. M., \& Harris, R. J. (2003). Perceptions of effectiveness of response to sexual harassment in US military, 1988 and 1995. Gender, Work and Organization, 10, 42-64.

Gallivan Nelson, C., Halpert, J. A., \& Cellar, D. F. (2007). Organizational responses for preventing and stopping sexual harassment: effective deterrents or continued endurance? Sex Roles, 56, 811-822.

Gruber, J. E. (1990). Methodological problems and policy implications in sexual harassment research. Population Research and Policy Review, 9, 271-298.

Gruber, J. E. (1998). The impact of male work environments and organizational policies on women's experiences of sexual harassment. Gender \& Society, 3, 301-320.

Gruber, J. E., \& Morgan, P. (2005). In the company of men: Male dominance and sexual harassment. York: Maple.

Gutek, B. A., Cohen, A. G., \& Konrad, A. M. (1990). Predicting social-sexual behavior at work: a contact hypothesis. Academy of Management Journal, 33, 560-577.

de Haas, S., Zaagsma, M., Höing, M., Berlo, W., \& van Vanwesenbeeck, I. (2007). Omgangsvormen, werkbeleving en diversiteit bij de Nederlandse politie anno 2006 [Sexual harassment and bullying, experience in work, and diversity in the Dutch police force in 2006]. Delft: Eburon.

Harned, M. S., Ormerod, A. J., Palmieri, P. A., Collinsworth, L. L., \& Reed, M. (2002). Sexual assault and other types of sexual harassment by workplace personnel: a comparison of antecedents and consequences. Journal of Occupational Health Psychology, 7, 174-188.

Hulin, C. L., Fitzgerald, L. F., \& Drasgow, F. (1996). Organizational influences on sexual harassment. In M. S. Stockdale (Ed.), Sexual harassment in the workplace (pp. 127-151). Thousand Oaks: Sage.

Ilies, R., Hauserman, N., Schwochau, S., \& Stibal, J. (2003). Reported incidence rates of work-related sexual harassment in the United States: using meta-analysis to explain reported rate disparities. Personnel Psychology, 56, 607-631.

Jackson, R. A., \& Newman, M. A. (2004). Sexual harassment in the federal workplace: influences on sexual harassment by gender. Public Administration Review, 64, 705-717.

Kauppinen-Toropainen, K. (1991). Miehet naisvaltaisissa ja naiset miesvaltaisissa ammateissa: Ainokaisaseman analyysi [Men in female dominated and women in male-dominated occupations: An analysis of token status]. Tyo ja Ihminen, 3, 218-238.

Kauppinen, K., \& Patoluoto, S. (2005). Sexual harassment and violence toward policewomen in Finland. In J. E. Gruber \& P. Morgan (Eds.), In the company of men: Male dominance and sexual harassment (pp. 195-214). York: Maple.

Kolner, C., Nauta, O., Soomeren, P., \& van Steinmetz, C. (2006). Goede praktijken tegen geweld. Preventie en bestrijding van ongewenste omgangsvormen op de werkplek. [Good practices against violence. Preventive and curative measures to tackle workplace harassment]. Amsterdam: DSP-Groep. 
Lee, D. (2000). Hegemonic masculinity and male feminisation; the sexual harassment of men at work. Journal of Gender Studies, 9, 141-155.

Magley, V. J., Waldo, C. R., Drasgow, F., \& Fitzgerald, L. F. (1999). The impact of sexual harassment on military personnel: is it the same for men and women? Military Psychology, 11, 283-302.

Martin, C. (1996). The impact of equal opportunities policies on the day-to-day experiences of women police constables. British Journal of Criminology, 36, 510-528.

Newman, M. A., Jackson, R. A., \& Baker, D. D. (2003). Sexual harassment in the federal workplace. Public Administrative Review, 63, 472-483.

Ott, E. M. (1989). Effects of the male-female ratio at work. Psychology of Women Quarterly, 13, 41-57.

Rutherford, S., Schneider, R., \& Walmsley, A. (2006). Ministry of Defence/Equal Opportunities Commission Agreement on Preventing \& Dealing Effectively with Sexual Harassment: Quantitative \& Qualitative Research into Sexual Harassment in the Armed Forces. Hampshire: Schneider-Ross.

Sandfort, T., \& Vanwesenbeeck, I. (2000). Omgangsvormen, werkbeleving en diversiteit bij de Nederlandse politie [Sexual harassment and bullying, experience in work, and diversity in the Dutch police force]. Delft: Eburon.

Sbraga, T. P., \& O’Donohue, W. (2000). Sexual harassment. Annual Review of Sex Research, 11, $258-285$.

Timmerman, G. (2005). The impact of male domination on the prevalence of sexual harassment: An analysis of European Union surveys. In J. E. Gruber \& P. Morgan (Eds.), In the company of men: Male dominance and sexual harassment (pp. 171-194). York: Maple.

Timmerman, G., \& Bajema, C. (2000). The impact of organizational culture on perceptions and experiences of sexual harassment. Journal of Vocational Behavior, 57, 188-205.

Transact and Rutgers Nisso Group. (2007). retrieved at 14 November 2007 at http://www.platformseksueleintimidatie. $\mathrm{nl} /$ vertrouwenspersoon.

Willness, C. R., Steel, P., \& Lee, K. (2007). A meta-analysis of the antecedents and ceonsequences of workplace sexual harassment. Personnel Psychology, 60, 127-162. 